\title{
Método canguru e aleitamento materno: uma revisão integrativa da literatura nacional
}

\author{
Kangaroo method and breastfeeding: an integrative review of national literature
}

\author{
Danielle da Costa Souto ${ }^{1}$, Márcia Elisa Jager², Amanda Schreiner Pereira ${ }^{3}$, \\ Ana Cristina Garcia Dias ${ }^{4}$
}

\begin{abstract}
RESUMO
Objetivo: Objetivou-se obter um panorama de estudos empíricos nacionais que discutam a prática do aleitamento materno durante a realização do Método Canguru (MC).

Materiais e Métodos: Os dados provem de uma revisão integrativa de literatura nacional. A busca foi realizada em quatro bases de dados nacionais interdisciplinares: Biblioteca Virtual de Saúde, Scielo, Scielo Brasil e Pepsic. Foram realizados cruzamentos triplos entre os descritores "aleitamento materno", "método canguru", "amamentação", "mãe canguru" e "humanização da assistência".

Resultados: Nos estudos encontrados investigaram-se vivências, percepções e experiências da prática do aleitamento materno durante o MC; sua relação com o desmame; as técnicas de aleitamento e o reflexo de sucção desenvolvido durante o método, bem como sua relação com o aleitamento materno no crescimento e ganho de peso do recémnascido prematuro. Os principais resultados apontam: a importância do contato pele a pele durante o MC e das representações sociais vinculadas ao leite e aleitamento materno; a necessidade de desenvolvimento de técnicas e complementação alimentar durante o método e a atenção aos fatores que influenciam no desmame ou prolongamento da amamentação.

Conclusão: Entre as conclusões, destaca-se a necessidade de pesquisas que investiguem aspectos psicológicos e suas variáveis no $\mathrm{MC}$, além dos físicos e biológicos. São escassos os estudos sobre a experiência materna malsucedida, por diferentes motivos, na prática da amamentação durante o MC. Atenta-se para a necessidade de disseminação do modelo hegemônico de maternidade que atravessa a experiência feminina.
\end{abstract}

Palavras-chave: método canguru; aleitamento materno; humanização da assistência; revisão.

\begin{abstract}
Objective: It was aimed at getting an overview of national empirical studies that discuss the breastfeeding practice during the implementation of Kangaroo Method (KM).

Materials and Methods: Data comes from an integrative review of national literature. The search was carried out in four national interdisciplinary databases: Virtual Health Library, SciELO, SciELO Brazil and Pepsic. Triple crosses were performed between the descriptors "breastfeeding", "kangaroo method", "breast-feeding", "kangaroo mother" and "humanization of assistance".

Results: In the studies found, some aspects were investigated such as, the experiencing acts, perceptions, and experiences of breastfeeding practice during KM; its relation with weaning; the breastfeeding techniques and the sucking reflex developed during the method, as well as its relation with the breastfeeding in the growth and weight gain of the preterm infant. The main results show: the importance of skin-to-skin contact during the KM and the social representations related to milk and to breastfeeding; the need for developing techniques and food supplementation during the method and attention to the factors that influence on weaning or on the lengthening of breastfeeding.

Conclusion: Among the conclusions, it is highlighted the need for researches which investigate psychological aspects and their variations in the KM, besides the physical and physiologic aspects. Studies about failing mother experiences are scarce, for different reasons, in the breastfeeding practice during the KM. It is observed the need for the dissemination of the hegemonic model of maternity which lies across the female experience.
\end{abstract}

Keywords: kangaroo method; breastfeeding; humanization of assistance; review.

\footnotetext{
${ }^{1}$ Psicóloga. Especialista em Saúde Mental e Atenção Psicossocial pela Universidade Luterana do Brasil (ULBRA). Discente do Programa de Pós Graduação em Psicologia, Universidade Federal de Santa Maria (UFSM).

${ }^{2}$ Psicóloga. Mestre em Psicologia da Saúde pela UFSM. Especialista em Gestão de Pessoas e Marketing pelo Centro Universitário Franciscano, Santa Maria.

${ }^{3}$ Psicóloga. Mestre em Distúrbios da Comunicação Humana pela UFSM. Docente na Universidade Luterana do Brasil (ULBRA), Santa Maria.

${ }^{4}$ Psicóloga. Doutora em Psicologia Escolar e do Desenvolvimento pela Universidade de São Paulo. Docente no Programa de Pós Graduação em Psicologia (UFSM).
} 


\section{INTRODUÇÃO}

Dados do Ministério da Saúde revelam que, em todo mundo, nascem anualmente 20 milhões de crianças prematuras e com baixo peso, sendo que um terço destas morrem antes de completar um ano de vida ${ }^{1}$. No Brasil, a principal causa de mortalidade infantil em crianças prematuras e de baixo peso ao nascer são as afecções perinatais, que compreendem problemas respiratórios, asfixia ao nascer e infecções. Em decorrência disto, o Brasil vem construindo uma nova visão sobre o assunto - a da atenção humanizada à criança, à mãe e à família² .

A humanização do nascimento deve ser iniciada já no acompanhamento pré-natal e persistir até o período pós-parto. O acompanhamento pré-natal, comumente, se caracteriza por, no mínimo, seis consultas de acompanhamento, exames laboratoriais e atividades educativas juntamente a outras gestantes. No que se refere ao período pós-parto, é comum que as ações envolvam a garantia de condições hospitalares (físicas, ambientais e humanas) adequadas, capacitações e treinamento profissional para garantir a segurança técnica da equipe multidisciplinar. Em relação especialmente ao papel da equipe multidisciplinar, destaca-se sua responsabilidade pela assistência ao recém-nascido e pela aproximação, o quanto antes possível, entre mãe e o bebê ${ }^{1,2,3}$. Esta aproximação é importante para o fortalecimento do vínculo afetivo, bem como para estimular o reflexo de sucção ao peito, necessário ao desenvolvimento do aleitamento materno. Quando o nascimento é prematuro, a equipe também deve garantir 0 acesso aos cuidados especializados necessários para a atenção humanizada ao recémnascido de risco ${ }^{4,5}$.

A prática de cuidados humanizada com a mãe e o recém-nascido prematuro ou de baixo peso proporcionou a implantação do MC no Brasil, em 1991. A primeira instituição brasileira a aderir a esta proposta foi o Hospital Guilherme Álvaro, localizado na cidade de Santos, São Paulo. Dados do Ministério da Saúde não indicam informações atualizadas sobre o número de hospitais brasileiros que contam com o MC. A última informação data de 2009, quando existiam 328 hospitais com equipes capacitadas para desenvolver o método.
Mas destaca-se que o MC pode ser implantado em todos os hospitais que tenham acesso às normas gerais da técnica e recursos necessários para a adoção do método $6,7,8,9$.

O MC é um sistema que permite o contato pele a pele entre a mãe e o bebê prematuro, oportunizado através de uma faixa de sustentação que envolve o bebê ao corpo da mãe, em posição vertical. Este método apresenta algumas vantagens em relação ao método tradicional (incubadora) de cuidado aos bebês prematuros ou de baixo peso ao nascer. A principal delas é o aumento do vínculo mãe e filho devido ao menor tempo de separação entre ambos e a exposição prolongada do bebê à estimulação sensorial. Isso possibilita a ocorrência frequente do aleitamento materno (em casos nos quais é possível a prática da amamentação), pois oferece à mãe a possibilidade de se sentir mais segura para amamentar o filho, mesmo após a alta hospitalar. Essas experiências são menos frequentes através da utilização do método tradicional $^{1,8,9}$.

O MC deve acontecer em três etapas: em um primeiro momento, o bebê, logo após o nascimento, é internado na Unidade de Terapia Intensiva Neonatal (UTIN). Durante sua internação, a mãe e familiares recebem informações sobre as condições de saúde do bebê, os procedimentos hospitalares que estão sendo realizados e as orientações sobre a amamentação e os cuidados que se deve ter com o recém-nascido prematuro. Nesta etapa é importante estimular os pais a terem contato tátil com o filho para estimular a criação do vínculo físico e afetivo entre familiares e prematuro $^{1,9}$

Em um segundo momento, em casos onde o recémnascido se encontra com a saúde mais estabilizada e já apresenta ganho de peso, ele pode ser transferido da UTIN para um alojamento/enfermaria conjunto (a) ou unidade de cuidado canguru. Neste local poderá ser iniciado o MC. A participação da mãe acontece através da posição canguru (bebê envolto ao corpo materno). A mãe receberá algumas instruções e poderá aprender a identificar as alterações que poderão ocorrer com a criança, como pausas respiratórias, mudanças de coloração de pele, entre outras. É importante destacar 
que para a realização adequada do $\mathrm{MC}$, a mãe deve renunciar parte de suas responsabilidades diárias, visto que deverá passar uma parcela significativa do seu tempo junto ao hospital. Com isto, podem ocorrer alterações na rotina, mudanças de papéis e reestruturação na dinâmica familiar. Por estes motivos, quando a equipe de saúde reconhece o MC como uma estratégia interessante para o desenvolvimento do bebê, a mãe e os familiares devem estar disponíveis para investir no processo ${ }^{1,7,10}$.

A terceira etapa do método ocorre na casa da família, após a alta hospitalar. É importante destacar que para ter alta do hospital, o bebê deve pesar no mínimo $1.500 \mathrm{~g}$ e ter a capacidade de sucção exclusiva no peito (nos casos onde é possível a mãe amamentar). A partir disso, o acompanhamento passa a ser ambulatorial e periódico, até que o bebê atinja o peso de $2.500 \mathrm{~g}$. Este acompanhamento consiste na realização de exames físicos e verificação do andamento do desenvolvimento da criança ${ }^{1,3,9}$.

Um aspecto valorizado e estimulado durante o MC é o processo de aleitamento materno. Isto porque, nas condições de prematuridade, o leite torna-se um forte aliado para a recuperação do bebê, auxiliando no seu desenvolvimento biológico e psicológico. Ao se colocar o bebê em posição canguru, fazendo contato com o corpo da mãe, ele encontrará o seio materno. O ato de prover o leite ao bebê através do seio promove ganhos físicos e psíquicos. No que se refere aos ganhos físicos, destaca-se que o leito humano é uma das principais formas de contribuição para o desenvolvimento e crescimento da criança, principalmente para as crianças que apresentam baixo peso ao nascer e/ou são prematuras. Especialmente neste contexto, o leite possui um valor nutricional superior a qualquer outro tipo de leite, funcionando como fonte de alimento e de proteção contra doenças ${ }^{11}$.

Já no que se refere aos ganhos psíquicos, destaca-se que a prática da amamentação é uma das principais formas que auxilia na formação do vínculo afetivo entre a mãe e o filho. Este vínculo é importante que se estabeleça, pois o desenvolvimento físico e psicológico da criança será influenciado por estes primeiros contatos entre mãe e bebê, proporcionando uma importante estimulação afetiva e cognitiva para a criança $^{12,13}$

A partir do exposto sobre a relação entre o $M C$ e o aleitamento materno, o presente estudo busca identificar a área do conhecimento predominante e o que vem sendo investigado por pesquisas nacionais sobre a prática da amamentação durante o $\mathrm{MC}$ e os principais resultados encontrados. Identificar a área do conhecimento predominante em pesquisas nacionais sobre MC é importante na medida em que se terá um "estado da arte" sobre o tema. Internacionalmente, o MC e sua relação com o aleitamento materno é amplamente discutido e divulgado no meio científico, o que foi identificado através de uma busca no Portal de Periódicos da Capes e no PsycINFO. Entretanto, nacionalmente, pesquisas sobre a temática ainda precisam avançar, uma vez que a implantação do MC em algumas localidades e hospitais brasileiros ainda encontra-se em processo de instauração. Neste sentido, o mapeamento de estudos brasileiros que discutam o MC e sua relação com o aleitamento materno permite identificar as áreas expoentes e as possíveis carências teóricas que poderiam auxiliar no entendimento sobre a temática e avançar nos processos que envolvem o MC. Já a identificação de objetivos e resultados dos estudos pode auxiliar na percepção geral sobre o que já foi pesquisado e os principais resultados apontados pelas pesquisas. Com isto é possível identificar problemas de pesquisa pouco discutidos ou que ainda não foram explorados pela literatura nacional, uma vez que esta vem se mostrando deficiente em estudos na área. Esta identificação pode revelar temas potenciais para futuras pesquisas e novos achados.

\section{MATERIAIS E MÉTODOS}

Realizou-se, durante o mês de agosto de 2012, uma revisão integrativa da literatura nacional publicada entre os anos de 2002 a 2012 sobre a prática do aleitamento materno durante a realização do MC. A busca foi realizada em quatro bases de dados nacionais interdisciplinares: Biblioteca Virtual de Saúde (http://regional.bvsalud.org/), Scielo (http://www. scielo.org/) Scielo Brasil (http://www.scielo.br/) e Pepsic 
(http://pepsic.bvsalud.org/). Foram realizados cruzamentos triplos entre os descritores "aleitamento materno", "método canguru", "amamentação", "mãe canguru" e "humanização da assistência". Estes descritores foram escolhidos com base na busca nos Descritores em Ciências da Saúde - DeCs (http://decs.bvs.br/) e pela frequência com que são utilizados em artigos sobre a temática.

Para os estudos encontrados nas bases de dados serem incluídos na análise, utilizaram-se os seguintes critérios: estar em formato de artigo, ser nacional, empírico, estar publicado na íntegra e na última década e apresentar como objetivo principal a discussão sobre a prática do aleitamento materno durante a realização do MC. Excluíram-se todos os estudos que não respondiam a estes critérios.

Para análise dos artigos foi necessária organização prévia do material, na qual todos os artigos selecionados foram inicialmente compilados para leitura completa e posterior registro em três eixos: (1) área de conhecimento, (2) objetivos e (3) principais resultados. O material foi analisado através da técnica de análise de conteúdo temática, conforme proposta de Bardin ${ }^{14}$.

\section{RESULTADOS}

No total, foram encontrados 159 artigos relacionados ao tema do aleitamento materno durante a prática do MC: a base de dados Biblioteca Virtual de Saúde recuperou o total de 88 estudos; a base de dados Scielo forneceu um total de 61 artigos; a busca na base de dados Scielo Brasil recuperou 10 artigos e na base de dados Pepsic não foram recuperados artigos sobre o tema. Dos 159 estudos recuperados nas quatro bases de dados, 124 artigos apareciam em duas ou mais bases de dados (duplicados). Neste sentido, consideraram-se apenas os estudos que apareceram pelo menos uma vez nas bases consultadas, ou seja, 35 artigos.

Dos 35 artigos selecionados, dois estudos haviam sido publicados há mais de dez anos, dois foram desenvolvidos no exterior, cinco se referiam a revisões de literatura, cinco possuíam acesso restrito ao texto completo e 11 não tinham como objetivo discutir a prática do aleitamento materno durante a realização do
MC. Após a etapa de exclusão dos artigos, a análise final contou com 10 artigos, os quais continham como objetivo discutir sobre a prática do aleitamento materno durante o MC.

Os resultados foram organizados a partir dos três eixos temáticos definidos: área de conhecimento, objetivos e principais resultados (ver tabela 1 Apresentação dos Resultados). Esta sistemática de apresentação dos resultados oportuniza um panorama geral da área do conhecimento predominante, dos objetivos e dos principais resultados encontrados em estudos nacionais sobre a prática da amamentação durante o MC publicados na última década.

\section{Área de conhecimento}

A análise da área de conhecimentos nas quais os estudos estavam vinculados demonstra que três deles foram desenvolvidos por pesquisadores da Medicina 15,16,17; quatro da Enfermagem ${ }^{18,19,20,21}$; dois da Fonoaudiologia ${ }^{22,23}$ e um deles da Fisioterapia ${ }^{24}$. Todos os estudos vinculavam-se à área das Ciências da Saúde.

\section{Objetivos}

Os objetivos foram organizados nas quatro categorias descritas na tabela 1. Cada categoria aborda o número de artigos encontrados e as especificações das características dos objetivos dos estudos.

\section{A prática do aleitamento materno durante a realização} do $M C$

Esta categoria congrega cinco estudos que apresentam objetivos semelhantes. Um deles ${ }^{21}$ buscou identificar as representações sociais de mães sobre o aleitamento materno dos bebês pré-termo, em uma unidade de cuidado canguru (segunda etapa do MC). Outro estudo ${ }^{24}$ avaliou eficácia do conhecimento adquirido pelas mães sobre a amamentação exclusiva no contexto do MC na pré a pós-alta.

Outros três estudos ${ }^{15,19,20}$ buscaram compreender, conhecer e diferenciar as percepções, experiências e vivências entre mães em processo de aleitamento materno exclusivo de seus filhos prematuros em momentos distintos: diferenciação no aleitamento 
TABELA 1 - Apresentação dos resultados.

\begin{tabular}{ccc}
\hline & Área de Conhecimento & \\
\hline & & Medicina $^{15,16,17}$ \\
Ciências da Saúde & Enfermagem $^{18,19,20,21}$ \\
& Fonoaudiologia $^{22,23}$ \\
& Fisioterapia & \\
\hline Categorias & Objetivos & Especificações
\end{tabular}

A prática do aleitamento materno durante a realização do MC $^{15,19,20,21,24}$

A relação do $\mathrm{MC}$ com o desmame ${ }^{16,22}$

Técnicas de amamentação e o reflexo de sucção desenvolvido durante o $\mathrm{MC}^{17,23}$

A relação entre o $\mathrm{MC}$ e aleitamento materno e ganho de peso do recém-nascido ${ }^{18}$
Vivências, percepções e experiências da amamentação durante o período em que as mães participaram do método.

Fatores que podem interferir no desmame de bebês prematuros em MC durante a internação e após a alta hospitalar.

Recursos que podem auxiliar na sucção do bebê prematuro durante o MC

Amamentação e ganho de peso de bebês prematuros participantes do MC.

\section{Principais Resultados dos Estudos}

\section{Categorias de Resultados}

A importância do contato pele a pele e as representações sociais do aleitamento materno e do leite materno por mães em MC $^{16,19,20,22,24}$

Técnicas e complementação alimentar durante o $\mathrm{MC}^{18,21,24}$

Fatores que influenciam no desmame ou no prolongamento da amamentação por mães que participaram do $\mathrm{MC}^{16,22}$

\section{Especificações}

Significado do aleitamento materno e do leite materno para as mães e da estimulação do contato pele a pele oferecida durante o MC.

Técnicas (uso do copinho) utilizadas para a alimentação (amamentação indireta - leite materno oferecido ao bebê através de técnicas específicas) do recém-nascido prematuro.

Fatores que podem influenciar na ocorrência ou não do desmame precoce e na continuidade da amamentação antes e depois da alta hospitalar. materno no intervalo entre o $4^{\circ}$ e $\circ 6^{\circ}$ mês de vida do bebê e entre mães que não optaram pela prática do $\mathrm{MC}^{15}$; as dificuldades maternas durante a prática do método na unidade/alojamento canguru ${ }^{19}$ e durante a internação hospitalar do bebê ${ }^{20}$.

\section{A relação do $\mathrm{MC}$ com o desmame}

Esta categoria apresenta dois estudos com objetivos similares. Estes estudos procuraram mostrar a prevalência, as variáveis maternas e as causas de desmame em recém-nascidos participantes do MC. Para tal, identificou-se a ocorrência do desmame precoce em uma maternidade escola e os fatores que influenciaram no desmame durante a internação e após a alta hospitalar (segunda e terceira etapa do MC) de uma maternidade pública ${ }^{22}$. Também se buscou identificar, em ambos os períodos, os fatores para futuras intervenções no desmame: aprimoramento das técnicas envolvidas no MC e atendimento ao recémnascido prematuro ${ }^{16}$.

Técnicas de amamentação e o reflexo de sucção desenvolvido durante o MC

Dois estudos ilustram essa categoria. Um deles ${ }^{17}$ buscou comparar o processo de sucção em bebês prematuros durante a segunda etapa do MC daqueles que não foram submetidos às técnicas de amamentação oferecidas pelo método. Já outro estudo ${ }^{23}$ avaliou o manejo do copinho (técnica de oferta de leite materno) por mães que estavam no alojamento conjunto (segunda etapa do MC), analisando os fatores que contribuem para a administração adequada da técnica. 
A relação entre $M C$ e aleitamento materno no crescimento e ganho de peso do recém-nascido

Apenas um artigo se preocupou em relacionar o MC com a prática do aleitamento materno e o desenvolvimento físico do bebê. $\mathrm{O}$ estudo ${ }^{18}$ analisou a avaliação pondero-estatural (avaliação do crescimento e ganho de peso dos recém-nascidos prematuros) no alojamento canguru (segunda etapa do MC). O estudo também se preocupou em verificar a influência do aleitamento materno exclusivo no ganho de peso destes bebês.

\section{Principais resultados dos estudos}

Os principais resultados dos artigos analisados são apresentados através das três categorias descritas na tabela 1. Estas categorias foram organizadas de acordo com as categorias de objetivos descritas anteriormente, visto a correlação entre objetivos dos estudos e resultados encontrados.

Os principais resultados encontrados através da investigação dos objetivos apresentados na categoria "A prática aleitamento materno durante a realização do MC" estão relacionados com a categoria de resultados "A importância do contato pele a pele e as representações sociais do aleitamento materno e do leite materno por mães em MC".

A categoria apresentada nos objetivos denominada "Técnicas de amamentação e o reflexo de sucção desenvolvido durante o MC" e a categoria "A relação do MC e do aleitamento materno com o crescimento e ganho de peso do recém-nascido" podem ser relacionadas à categoria de resultados "Técnicas e complementação alimentar durante o MC". A categoria de objetivos "A relação do MC com o desmame", se relaciona à categoria de resultados "Fatores que influenciam no desmame ou no prolongamento da amamentação por mães que participaram do MC".

A importância do contato pele a pele $e$ as representações sociais do aleitamento materno e do leite materno por mães em MC

Os resultados dos estudos que se preocuparam em investigar 0 aleitamento materno durante $0 \mathrm{MC}$ encontraram que $o$ aleitamento materno ajuda a estimular o contato da mãe com o filho e a construção do vínculo mãe-bebê. O uso da mamadeira foi visto por algumas mães como um obstáculo para a formação deste vínculo, sendo relacionada com superficialidade na relação com o filho ${ }^{24}$. Ainda, mães participantes dos estudos relacionam o aleitamento materno à saúde do bebê, seja ele prematuro ou não. Para elas, o leite materno é importante para o crescimento e desenvolvimento, podendo auxiliar no ganho de peso, recuperação do bebê prematuro e alta hospitalar ${ }^{22,24}$.

Outros resultados mostram que o contato do bebê com a mãe e o estímulo pele a pele, possíveis através do MC, funcionam como dispositivos eficientes para o estímulo de sucção direta do bebê ao seio materno 16,19,20,22. Entretanto, um dos estudos analisados ressalta que existe tendência das mães deixarem de praticar a posição canguru após a alta hospitalar. Este comportamento pode trazer consequências para a prática da amamentação. Mesmo reconhecendo os benefícios da prática, as mães deixam de realizá-la, pois comumente passam a ser uma das únicas responsáveis pelos cuidados do bebê. Isto pode ser relacionado ao fato de que ao retornar para casa e para sua rotina familiar e social, as mães podem disponibilizar menos tempo e disposição para a prática do $\mathrm{MC}^{24}$.

\section{Técnicas e complementação alimentar durante o MC}

Os resultados dos estudos que investigaram técnicas de amamentação e o reflexo de sucção desenvolvido durante $\mathrm{O} \mathrm{MC}$ e a relação do método e do aleitamento materno com o crescimento e ganho de peso do recémnascido encontraram resultados interessantes. Mostram que no período onde a mãe e o bebê prematuro se encontram na unidade de cuidado canguru ou enfermeira/alojamento conjunto (segunda etapa do $\mathrm{MC})$, as mães aprendem a oferecer seu próprio leite como complemento durante as mamadas. Como o recém-nascido prematuro tem dificuldades em sugar o leite diretamente do seio materno, essa complementação pode ser oferecida através do uso da técnica do copinho ou de uma colher ${ }^{18,21}$. O uso do copinho auxilia para o futuro estabelecimento da amamentação exclusiva, uma vez que possibilita o bebê desenvolver o reflexo de sucção a partir do movimento 
lingual que realiza para acessar o leite que está no $\mathrm{copo}^{24}$.

As mães também são auxiliadas pelos profissionais de saúde a realizar a ordenha mamária. A ordenha mamária consiste na oferta do leite materno ao bebê na hora da retirada do seio ou no armazenamento do leite em um banco de leite no hospital para que seu bebê ou outros bebês prematuros internados no hospital possam ser alimentados em outros momentos ${ }^{18,21}$.

Fatores que influenciam no desmame ou no prolongamento da amamentação por mães que participaram do $M C$

Os resultados de um dos estudos que investigou a relação do $\mathrm{MC}$ com o desmame encontrou que a maioria das mães que participaram do MC finalizaram a terceira etapa em amamentação exclusiva, mas quando retornam a domicilio com seus bebês e não estavam em contato direto com os profissionais de saúde, diminuíram a amamentação. Ficou evidente que os maiores índices de desmame ocorrem nesta época, pois é quando o cuidado do bebê deixa de estar sobre supervisão dos profissionais de saúde e depende exclusivamente da mãe e da família. Alguns fatores estão diretamente relacionados a essa diminuição, tais como: fatores socioculturais, econômicos, anatofisiológicos e psicoemocionais ${ }^{22}$.

Outro estudo realça fatores que podem postergar a interrupção da amamentação exclusiva por mães que participaram do MC. Entre esses fatores, destaca-se: permanência prolongada da mãe nas unidades de cuidado canguru em decorrência de ganho de peso de o bebê evoluir lentamente e a prática da ordenha mamária. No que se refere à permanência prolongada da mãe nas unidades onde acontece o MC argumentase que quanto menor o peso do bebê, mais tarde a mãe deixará de amamentá-lo. Isto porque o leite materno, como discutido anteriormente, tem poder de auxiliar no crescimento e desenvolvimento do bebê prematuro. No que diz respeito à ordenha mamária, esta é capaz de postergar a ocorrência do desmame, pois a retirada do leite por esse meio permite a manutenção da lactância ${ }^{16}$.

\section{DISCUSSÃo}

No eixo temático "Área de conhecimento", percebe-se que todos os artigos analisados foram desenvolvidos por pesquisadores vinculados à área da saúde. Entretanto, chama-se atenção para a relevância que outras áreas do conhecimento, a citar a área das Ciências Humanas, podem trazer para a efetivação e eficácia do MC. Para exemplo disto têm-se as contribuições da Psicologia (em Universidades onde ela faz parte das Ciências Humanas, uma vez que ela também pode estar vinculada à Ciências da Saúde). A atuação do psicólogo como profissional ativo durante a realização do $\mathrm{MC}$ pode trazer bons resultados. Como já mencionado, o MC é uma política de humanização hospitalar ${ }^{25}$, e a inserção do psicólogo neste contexto, apesar de recente, pode contribuir para a qualidade do método ${ }^{26}$.

A atuação do psicólogo no hospital onde é realizado o MC é recomendada pela Fundação Orsa, que apóia a implantação do método ${ }^{27}$. De fato, o psicólogo pode possibilitar a expressão e a partilha de vivências das mães-cangurus, possibilitando uma melhor elaboração de sentimentos comumente presentes durante a aplicação do método, como ansiedades específicas, estresse e sofrimento. Isto pode proporcionar melhores condições de enfrentamento, re-significando essa experiência ${ }^{28}$. Assim, é importante destacar que a Psicologia é uma área do conhecimento capaz de contribuir em pesquisas sobre o tema, uma vez que investiga experiências valorizadas pelo MC, como a prática do aleitamento materno e a formação do vínculo mãe-bebêt 27

O eixo temático "Objetivos" nos mostra que cinco estudos ${ }^{15,19,20,21,24}$ se preocuparam em investigar as vivências, experiências e percepções de mães durante a prática do aleitamento materno na realização de todas as etapas do MC. Os demais estudos investigaram a relação do $\mathrm{MC}$ com o desmame durante a internação e após alta hospitalar ${ }^{16,22 ;}$ o auxílio de técnicas de amamentação para o desenvolvimento do reflexo de sucção durante o $M^{17,23}$ e as relações estabelecidas entre MC, a prática do aleitamento materno e crescimento do bebê ${ }^{18}$. 
A alimentação é um direito da criança. Neste sentido, comumente, cabe à mãe alimentar seu bebê (seja pela amamentação exclusiva (seio materno), ou qualquer outra técnica ou recurso). Para tanto, é importante investigar vivências, experiências e percepções de mães sobre a prática do aleitamento materno durante o MC, uma vez que esta prática é atravessada por fatores pessoais, sociais e familiares ${ }^{29,30}$.

É fato que, além das qualidades fisiológicas do leite humano e seus benefícios físicos e biológicos, o mais duradouro benefício psicológico do aleitamento materno é formação do vínculo entre a mãe e o bebê. De fato, o recém-nascido prematuro, quando aninhado próximo à pele da mãe, pode ouvir o ritmo de seu batimento cardíaco, sentir o calor de seu corpo e, portanto, sentirse mais seguro e acolhido. Ainda, através do envolvimento afetivo é possível que a mãe aprenda a perceber e sentir as necessidades da criança, respondendo à demanda do bebê e oportunizando o seu desenvolvimento satisfatório ${ }^{31}$.

Entretanto, apesar da mãe ser percebida como fonte geradora do alimento infantil, é importante destacar que algumas mães não conseguem ou não podem amamentar. Estas mães se tornam mais vulneráveis ao aparecimento de sentimentos relacionados à culpa $\mathrm{e}$ frustração por não serem bem sucedidas nesse processo. Isto decorre, entre outros fatores, da comum associação realizada entre amamentação e oferta de amor materno. A mãe é o único ser humano capaz de gerar outro ser e o alimentar com uma substância gerada por seu próprio corpo - o leite humano. Isto faz com que a mãe seja percebida como uma figura divina e com responsabilidades maternas bem definidas, tais como o amor incondicional e o cuidado do bem estar do filho acima de tudo ${ }^{32}$. Neste contexto, amamentar passa significar amar e cuidar. Assim, mães que não querem (ou não podem) amamentar por diferentes motivos pessoais, sociais ou familiares podem sofrer culpa e preconceitos $^{33}$. Entretanto, sabe-se que é possível a alimentação infantil através da mamadeira. O leite oferecido à criança através da mamadeira supre suas necessidades físicas e biológicas e, quando investido de afeto, proporciona a mesma qualidade do vínculo afetivo entre mãe-bebê e oferece os mesmos benefícios psicológicos possibilitados através da amamentação pelo seio materno ${ }^{34}$. Isto indica a necessidade do reconhecimento do contexto biológico, psicológico e social do qual a mãe faz parte para a compreensão do processo de amamentação (seja pelo seio materno ou através de outro recurso, como a mamadeira) e fatores capazes de influencia-lo $0^{34,29,30}$

O leite humano e a amamentação são importantes para o desenvolvimento da criança. Porém, mais importante é como se dá o ato (comportamento) de amamentar, seja no peito ou na mamadeira. $A$ interação positiva entre mãe e bebê é o que realmente fará a diferença no desenvolvimento psicoafetivo dos filhos. Por esses motivos faz-se importante conhecer as experiências e vivências das mães durante o $M C$, uma vez que a ideia do método é beneficiar mãe e bebê através da amamentação. Entretanto, é importante lembrar que a amamentação é atravessada por diversos estímulos socioculturais, psicológicos e biológicos que podem interferir no processo, conforme descrito anteriormente. Assim, ao se reconhecer alguns desses aspectos torna-se possível atender melhor as necessidades das mães frente ao aleitamento materno ${ }^{34}$.

Outros dois estudos ${ }^{15,21}$ investigaram a relação do MC com o desmame na tentativa de identificar os fatores determinantes para a ocorrência tardia ou precoce da interrupção do aleitamento materno. Um aspecto capaz de adiar a interrupção do aleitamento materno é a realização da ordenha mamária. Esta é capaz de incentivar a lactação, onde as mães de recém-nascidos prematuros ou de baixo peso devem ser encorajadas e orientadas a realizá-la o quanto antes possível. Isto por que ao estimular a lactação ocorre produção de maior volume de leite, contribuindo para futuro estabelecimento da amamentação. $O$ atraso da expressão mamária e a inibição da ejeção de leite em decorrência da ansiedade e preocupação com o bebê, frequente em contextos onde a criança apresenta baixo peso ao nascer e/ou é prematura, configurando um fator de risco ao seu desenvolvimento, podem determinar a insuficiência láctea ${ }^{10,35}$.

É necessário considerar que, apesar de desejável e de já ter sido constatada a importância do aleitamento 
materno para bebês de baixo peso ao nascer e/ou prematuros, ainda existe pouco sucesso na prática e a prevalência de amamentação nesse grupo quando não associada ao MC. Isto é evidenciado por estudos que mostram que mães que optaram participar do método e que tiveram contato pele a pele com seus bebês apresentaram uma produção láctea mais estável e maior volume de produção de leite quando comparadas a mães que não participaram. Ainda, verificou-se que nestas últimas o abandono precoce da amamentação foi mais frequente $7,36,37$.

Outros dois estudos ${ }^{17,23}$ buscaram avaliar e analisar as técnicas de amamentação e o reflexo de sucção desenvolvido durante o MC. Recém-nascidos pré-termo nascem com reflexos imaturos, ocasionando coordenação deficiente dos mecanismos de sucção, deglutição e respiração. A coordenação desses reflexos não ocorre senão por volta de 32 a 34 semanas de gestação. Estes bebês são frequentemente incapazes de ingerir e tolerar uma alimentação em quantidades que mantenham o crescimento no período pós-natal, devido à pequena capacidade de seu estômago e à imaturidade funcional de seu trato gastrointestinal ${ }^{38}$.

Através das técnicas de amamentação estabelecidas durante o MC ocorre melhor desenvolvimento do processo de sucção dos recém-nascidos prematuros, preparando-os para o aleitamento no seio materno. Técnicas como o uso do copinho e da ordenha mamária estimulam a produção de leite materno e ajudam a evitar problemas no seio, como o empedramento do leite. O uso do copinho é recomendado para que não aconteça a confusão de bicos (mamadeiras, chupetas e seio materno) e que se possa administrar suplementos alimentares, e preferencialmente, o leite materno sem prejudicar o processo de sucção dos recém-nascidos ${ }^{39}$.

Um único estudo trouxe como objetivo principal a relação do $M C$ e do aleitamento materno para o crescimento e ganho de peso do recém-nascido ${ }^{18}$. Uma das principais funções do MC é estimular a mãe a amamentar exclusivamente com leite materno. Isso pode contribuir para o crescimento e ganho de peso do bebê prematuro. Em situação de fragilidade orgânica, causada pela prematuridade, o organismo materno é capaz de produzir um leite mais rico em nutrientes e componentes imunobiológicos, adequado as necessidades nutricionais deste bebê. Por esta razão a nutrição recomendada para o bebê prematuro deverá ser feita preferencialmente com o leite materno. Isto justifica a prática da amamentação ser um dos principais focos do $\mathrm{MC}^{10,37}$.

O eixo temático "Principais resultados" foi organizado de acordo com as categorias definidas no eixo temático "Objetivos". Assim, a partir dos principais resultados encontrados através da investigação dos objetivos encontrados na categoria "O aleitamento materno durante o MC", discute-se a importância do contato pele a pele no $\mathrm{MC}$ e as representações sociais do aleitamento materno e do leite materno por mães em MC.

Em relação à importância do contato pele a pele, destaca-se que a proximidade com 0 filho prematuro favorece a troca de afetividade e o estabelecimento do vínculo. Essa troca de calor humano entre o recémnascido e os familiares são pontos importantes para o fortalecimento do relacionamento familiar ${ }^{40}$. Quando o bebê recém-nascido, por motivos de saúde, precisa ser separado de sua família, principalmente de sua mãe, é comum que os laços afetivos sofram interferências negativas, prejudicando o posterior desenvolvimento psicoemocional do bebê ${ }^{7}$. De fato, existem evidências de que um contato íntimo da mãe com seu bebê prematuro podem interferir de maneira positiva na relação dessa criança com o mundo. A pele, como o maior órgão do corpo humano, recebe estímulos sensoriais de várias magnitudes, e o contato pele a pele, oportunizado no MC pode promover algumas mudanças, tanto para a mãe quanto para o bebê. $\mathrm{Na}$ mãe ocorre a redução de sintomas de estresse, principalmente em casos que necessitam de estadia hospitalar prolongada (como no caso do MC) e os bebês apresentam redução do choro aos seis meses de idade. O conhecido efeito do contato pele a pele também funciona como um estimulador da liberação de ocitocina (hormônio capaz de promover a ejeção do leite durante a amamentação) que parece desempenhar um importante papel no comportamento da mãe e afetar positivamente o seu humor, facilitando o contato $e$ relacionamento afetivo com o bebê ${ }^{1,7,41}$. 
No que se refere ao aleitamento materno e ao leite humano, existe a representação social de que a mãe que amamenta seu filho é vista como uma boa mãe e a que não o faz passa a ser vista como negligente. Essa dimensão da amamentação como inerente à condição materna denota a incorporação do discurso técnico difundido por meio de campanhas veiculadas pela mídia e de práticas assistenciais. Por isso, mesmo as mulheres que não desejam amamentar demonstram conhecer as propriedades do leite materno e sua influência no crescimento e desenvolvimento da criança. O reconhecimento do leite materno como fonte de saúde e recuperação do bebê prematuro ou de baixo peso parece ser universal ${ }^{42}$.

A partir das categorias "Técnicas de amamentação e reflexo de sucção desenvolvido durante o $M C$ " e "A relação do $\mathrm{MC}$ e do aleitamento materno no crescimento e ganho de peso do recém-nascido", estabelecidas na categoria dos objetivos, pode-se discutir sobre as técnicas e complementação alimentar durante a segunda etapa do MC.

O uso de algumas técnicas de aleitamento está diretamente relacionado ao desenvolvimento e ganho de peso do recém-nascido prematuro. Uma dessas técnicas é a alimentação por copinho, já descrita anteriormente, de forma breve. Algumas vantagens desta técnica são descritas na literatura, entre as quais se destacam: o método evita a confusão de bicos; permite o contato íntimo do bebê com a mãe ou com o cuidador; demonstra à mãe as competências do bebê; é um método simples, prático, de baixo custo e uma forma segura de alimentar; permite fácil esterilização; e favorece o início e a manutenção do aleitamento materno, inclusive após a introdução de novos alimentos. Por outro lado devem ser descritas as desvantagens, que são: risco de aspiração de leite em casos onde não for utilizada a técnica e a postura adequada do bebê, e risco de infecção se ocorrer manipulação inadequada do leite ${ }^{43,44}$.

Consequentemente, para que seja realizada a técnica do uso do copinho e o leite ingerido pelo recém-nascido seja o materno, é necessária a aprendizagem de outra técnica: ordenha mamária. Esta técnica consiste em uma massagem manual no seio para que seja realizado seu esvaziamento, evitando assim o empedramento do leite e alguma futura fisiologia da lactação. O leite ordenhado é destinado aos bancos de leite e a alimentação de bebês que estejam em internação hospitalar ${ }^{45}$.

Quanto ao reflexo de sucção, este pode ser estimulado através da técnica do uso do copinho na situação em que se encosta a borda do copo no lábio inferior do bebê. Isso será seguido de uma atividade lingual, observadas em bebês de 30 a 34 semanas de idade gestacional. Através disto, os bebês passam a lamber o copo, colocando a língua no leite, iniciando o processo de sucção. Posteriormente, essa atividade de língua será fundamental para a prática da amamentação ${ }^{43}$

É importante considerar que a amamentação é amplamente conhecida como a nutrição infantil ideal, mas para que aconteça de forma adequada, é necessário que a criança aprenda a prender o seio e a sugá-lo corretamente. Acredita-se que experiências orais prematuras (mamadeiras e chupetas) nas quais se usam mecanismos de sucção diferentes da amamentação no peito, sejam causadoras de uma imprópria "pega" e de problemas subsequentes na amamentação ${ }^{39}$.

Sobre a categoria "A relação com o MC com o desmame" pode ser discutido sobre os fatores que influenciam no desmame precoce ou no prolongamento da amamentação em mães participantes do método. $A$ terceira etapa do método (alta hospitalar onde 0 acompanhamento do bebê passa a ser ambulatorial) é o período em que mais ocorre o desmame. Acredita-se que o principal fator que interfere no desmame dos bebês que passaram pelo MC são os socioculturais. Devido ao nascimento prematuro do bebê e ele encontrar-se fora do ambiente hospitalar, familiares e a própria mãe podem acreditar que o leite materno não é suficiente para a satisfação do bebê. Assim, podem acabar introduzindo outros suplementos alimentares através da mamadeira e deixando de priorizar o aleitamento materno ${ }^{46}$.

A introdução da mamadeira e de chupetas pode ser outro fator que possibilite o desmame de crianças participantes do método. Isto porque, para muitos bebes 
pode ocorrer a chamada "confusão de bicos", já mencionada anteriormente. Isto pode dificultar a configuração oral correta (abertura de boca e posicionamento da língua), a "pega" adequada e o padrão de sucção necessários para um aleitamento materno eficiente. As experiências orais com bicos artificiais favorece o surgimento de mecanismos de sucção diferentes dos utilizados no aleitamento materno, podendo causar alteração na "pega" e fracasso no aleitamento 47 .

Como limitação deste estudo, destaca-se que a busca por estudos que relacionem o MC com o aleitamento materno ocorreu somente em âmbito nacional. Como sugestão de novas pesquisas sugere-se buscas sistemáticas em bases de dados internacionais para trazer outro panorama sobre o $\mathrm{MC}$ e os aspectos que perpassam o aleitamento materno. Fazer esta busca considerando bases de dados nacionais e internacionais tornaria o estado da arte sobre a temática proposta mais abrangente. Ainda, sugerem-se estudos que busquem fazer esta investigação mais completa e ousem comparar resultados e conclusões entre estudos nacionais e internacionais. Esta comparação pode trazer bons resultados e direcionamentos para a área de atuação em saúde materno-infantil.

A partir do exposto neste estudo pode-se concluir que as pesquisas sobre $0 \mathrm{MC}$ e sua relação com 0 aleitamento materno são marcadas por investigações predominantemente realizadas por pesquisadores vinculados à área da saúde. Ressalta-se também a escassez de estudos que discutam sobre a experiência de mães que não foram bem sucedidas na prática da amamentação durante $\mathrm{MC}$, que não conseguiram amamentar seus filhos através do seio materno e se utilizaram de outros tipos de métodos para tal objetivo. Pode-se perceber a forte relação entre o aleitamento materno e a concretização dos "deveres" maternos, onde amamentar parece estar atribuído ao fato de ser uma boa mãe e expressar amor incondicional pelo filho.

\section{REFERÊNCIAS}

1. Brasil. Ministério da Saúde. Secretaria de Atenção a Saúde. Departamento de Ações Programáticas Estratégicas. Atenção humanizada ao recém-nascido de baixo peso: método canguru. 2ed. Brasília (DF): Ministério da Saúde; 2011.

2. Brasil. Ministério da Saúde. Secretária Executiva Programa humanização do parto: humanização no prénatal e nascimento. Brasília (DF); 2002.

3. Carvalho MR, Prochnik M. Método mãe canguru de atenção ao prematuro. Rio de Janeiro: BNDES; 2001.

4. Ferreira NAES, Souza MCMR. O método mãe-canguru como instrumento de promoção do aleitamento materno exclusivo. NBC 2011;1(1):1-8.

5. Serruya SJ, Cecatti JG, Lago TG. O programa de humanização no pré-natal e nascimento do ministério da saúde no Brasil: resultados iniciais. Cad Saúde Pública 2004; 20(5):1281-9.

6. Diaz-Rossello J. Caring for the mother and preterm infant: kangaroo care. Birth 1996;23:108-11.

7. Venâncio SI, Almeida H. Método mãe canguru: aplicação no Brasil, evidências científicas e impacto sobre o aleitamento materno. J Pediatr 2004; 80(supl. 5): 173-80.

8. Cardoso ACA, Romiti R, Ramos JLA, Issler H, Grassiotto $\mathrm{C}$, Sanches MTC. Método mãe-canguru: aspectos atuais. Pediatria 2006; 28(2):128-34.

9. Moreira JO, Romagnoli RC, Dias DAS, Moreira CB. Programa mãe-canguru e a relação mãe-bebê: pesquisa qualitativa na rede pública de Betim. Psicol Estud 2009; 14(3):475-83

10. Nascimento MBR, Issler $\mathrm{H}$. Aleitamento materno em prematuros: manejo clínico hospitalar. J Pediatr 2004; 80(5):s163-s172.

11. Kummer SC, Giugliani ERJ, Susin LO, Folletto JL, Lermen NR, Wu VYJ, Santos L, Caetano MB. Evolução do padrão de aleitamento materno. Rev Saúde Pública 2000;34(2): 143-8.

12. Delgado SE. A construção do caminho do vínculo mãe adolescente/bebê pré-termo. Rev Bras Crescimento Desenvolv Hum 2002; 12(1):27-35.

13. Galvão MTG, Vasconcelos SG, Paiva SS. Mulheres doadoras de leite humano. Acta Paul Enferm 2006;19(2): 157-61.

14. Bardin L. Análise de conteúdo. Lisboa: Edições 70; 2004.

15. Braga DF, Machado MMT, Bosi MLM. Amamentação exclusiva de recém-nascidos prematuros: percepções e experiências de lactantes usuárias de um serviço público especializado. Rev Nutr 2008;21(3):293-302.

16. Silva SMS, Segre CAM. Fatores que influenciam o desmame no recém-nascido prematuro. Rev Bras Crescimento Desenvolv Hum 2010; 20(2):291-301.

17. Andrade ISN, Ferreira ZCF. Sucção do recém-nascido prematuro: comparação do método mãe-canguru com os cuidados tradicionais. Rev Bras Saude Mater Infant 2005; 5(1):61-9

18. Freitas JO, Camargo CL. Método mãe-canguru: evolução ponderal de recém-nascido. Acta Paul Enferm 2007; 20(1):75-81.

19. Rolim KMC, Vidal AF, Mariano MA, Campos ACS, Frota MA. Percepção das mães sobre aleitamento em prematuros da unidade canguru de uma maternidade de Fortaleza - CE. Rev RENE 2008; 9(2):54-63.

20. Neves PN, Ravelli APX, Lemos JRD. Atenção humanizada ao recém-nascido de baixo-peso (método mãe canguru): percepções de puérperas. Rev Gaúcha Enferm 2010; 31(1):48-54.

21. Javorski M, Caetano LC, Vasconcelos MGL, Leite AM, Scochi CGS. As representações sociais do aleitamento materno para mães de prematuros em unidade de cuidado canguru. Rev Latino-Am Enfermagem 2004;12(6):890-8. 
22. Alves AML, Silva ÉHAA, Oliveira AC. Desmame precoce em prematuros participantes do Método Mãe Canguru. Rev Soc Bras Fonoaudiol 2007;12(1):23-8.

23. Lima VP, Melo AD. Uso do copinho no alojamento canguru. Rev CEFAC 2008;10(1);126-33.

24. Chagas DO, Pereira MAS, Nicomedes TM, Lima RABC Azevedo VMGO, Gontijo FO. Comparação da adesão materna às orientações do método Mãe Canguru no pré e pós-alta do Hospital Sofia Feldman. Rev Med Minas Gerais 2011;21(1):5-8.

25. Veras RM, Traverso-Yépez MA. O cotidiano institucional do método mãe canguru na perspectiva dos profissionais de saúde. Psicol Soc 2011; 23(n. esp.):90-8.

26. Fongaro $\mathrm{MLH}$, Sebastiani RW. Roteiro de Avaliação psicológica aplicada ao hospital geral. In: AngeramiCamon VA organizador. Chiattone HBC, Sebastiani RW, Fongaro MLH, Santos CT. E a psicologia entrou no hospital. 5 ${ }^{\underline{a}}$ ed. São Paulo: Cengage Learning; 2011. p.555 .

27. Fundação Orsa. Programa de Disseminação de Atenção Humanizada ao Recém-nascido de Baixo Peso - método mãe canguru. As sustentações cotidianas das famílias envolvidas no método mãe-canguru. Fundação Orsa; 2005.

28. Brasil. Ministério da Saúde. Rede Humaniza SUS. Rede de colaboração para a humanização da gestão e da atenção no SUS. 2003 [acesso em: 22 nov. 2012]. Disponível em: http://www.redehumanizasus.net/

29. Machado MMT. A conquista da amamentação: o olhar da mulher [dissertação]. Fortaleza (CE): Universidade Federal do Ceará; 1999

30. Vannuchi MTO, Monteiro CA, Réa MF, Andrade SMDE, Matsuo T. Iniciativa Hospital Amigo da Criança e aleitamento materno em unidade de neonatologia. Rev Saúde Pública 2004;38(3):422-8.

31. Gonçalves DM, Pereira FK, Ohy JB, Leite LP, Kikuchi R, Emílio SA. O vínculo mãe-bebê na atualidade. Bol Inic Cient Psicologia 2006;7(1):112-22.

32. Arantes CLS. Amamentação: visão das mulheres que amamentam. J Pediatr 1995;71(4):195-202.

33. Silva AAM. Amamentação: fardo ou desejo? Estudo histórico social dos deveres e práticas sobre aleitamento na sociedade brasileira [dissertação]. Ribeirão Preto (SP): Faculdade de Medicina de Ribeirão Preto, Universidade de São Paulo; 1990.

34. Fromm K. Mães que não conseguem amamentar. 2010 [acesso em 22 nov. 2012]. Disponível em: http://www.personare.com.br/maes-que-nao-conseguemamamentar-m710

35. Jones E, Dimmock PW, Spencer SA. A randomised controlled trial to compare methods of milk expression after preterm delivery. Arch Dis Child Fetal Neonatal 2001; 85:91-5.
36. Bier JB, Ferguson A, Morales Y, Liebling JA, Archer D, Oh W, Vohr BR. Comparison of skin-to-skin contact with standard contact in low-birth-weight infants who are breast-fed. Arch Pediatr Adolesc Med 1996;150(12):12659.

37. Hill PD, Aldag JC, Chatterton RT. Effects of pumping style on milk production in mothers of non-nursing preterm infants. J Hum Lact 1999;15(3):209-16.

38. Leone CR, Pereira GR, Alves Filho N, Trindade Filho O. Nutrição do recém-nascido pré-termo. Rio de Janeiro: Medbook; 2008.

39. Howard CR, Blieck EA, Hoopen CB, Howard FM, Lanphear BP, Lawrence RA. Physiologic stability of newborns during cup-and bottlefeeding. Pediatrics 1999; 104(5):1204-7.

40. Furlan, CEFB, Scochi CGS, Furtado MCC. Percepção dos pais sobre a vivência no método mãe canguru. Rev Latino-Am Enfermagem 2003;11(4):444-52.

41. Matthiesen AS, Ransjo-Arvidson AB, Nissen E, UvnasMoberg K. Postpartum maternal oxytocin release by newborns: effects of infant hand massage and sucking. Birth 2001; 28(1):13-9.

42. Silva IA. Amamentar: uma questão de assumir riscos ou garantir benefícios. Rev Esc Enf USP 1996;30(1):170-1.

43. Lima GMS. Aleitamento materno em situações especiais. In: Rego JD. Aleitamento: um guia para pais e familiares. São Paulo: Atheneu; 2002. p. 153-78.

44. Gutierrez L, Delgado SE, Costa AP. Caracterização do uso da técnica do copo em UTIN de um hospital público. Rev Bras Crescimento Desenvolv Hum 2006;16(1):22-31.

45. Almeida JAG, Guimarães V, Novak FR. Normas técnicas para banco de leite humano: coleta. Centro de Referência Nacional para Bancos de Leite Humano Instituto Fernandes Figueira, Fundação Oswaldo Cruz. Brasília (DF): Ministério da Saúde; 2004.

46. Escobar AMU, Ogawa AR, Hiratsuka M, Kawashita MY, Teruya PY, Grisi S, Tomikawa SO. Aleitamento materno e condições socioeconômico-culturais: fatores que levam ao desmame precoce. Rev Bras Saude Mater Infant 2002; 2(3):253-61.

47. Neifert M, Lawrence R, Seacat J. Nipple confusion: toward a formal definition. J Pediatr 1995;126(6):125-9.

\section{Endereço para correspondência:}

Danielle da Costa Souto

Rua Dom Marcos Teixeira $n^{\circ} 240$

Santa Maria/RS - CEP 97095-430

Telefone: +55 5532265151

E-mail: daniellessouto@hotmail.com 